\title{
A rare presentation of acute fatty liver disease in pregnancy in the background of T-cell non-Hodgkin lymphoma
}

\author{
K A S U A Kodithuwakkua , N W Gunatilake ${ }^{\mathrm{b}}$, H R Manikgamaarachchic
}

\section{Introduction}

Lymphoma is the fourth most frequently diagnosed malignancy during pregnancy after melanoma, breast cancer and cervical cancer. The commonest type of lymphoma in pregnant women is Hodgkin lymphoma with a reported incidence ranging from 1 per 1,000 to 1 per 6,000 births ${ }^{1}$. Non-Hodgkin lymphoma (NHL) in pregnancy is rare and T-cell Non-Hodgkin lymphoma (T-NHL) is a rarer form of NHL with only a few reported cases to our knowledge. NHL in pregnancy is usually diagnosed during the second or third trimester and commonly associated with aggressive histology and disseminated disease. A rapid tumour growth is thought to occur in early pregnancy, puerperium and especially during lactation and reproductive organ involvement is common ${ }^{2,3}$.

Acute fatty liver disease (AFLD) in pregnancy is a rare condition and occurs in approximately one in 7,000 to one in 15,000 pregnancies $^{4}$. The cause is a deficiency of LCHAD (3-hydroxyacyl-CoA dehydrogenase) enzyme and the condition has an autosomal recessive inheritance pattern. The condition used to be universally fatal a couple of decades ago. However, due to the advancement in medicine, the case fatality rate has come down in recent years to $18 \%$ for the mother and $23 \%$ for the fetus ${ }^{4,5}$. Acute Fatty Liver Disease in Pregnancy in the background of NHL is an extremely rare occurrence and this is possibly the first-ever case reported to the best of our knowledge.

\section{Case}

A 35 year old woman with three healthy children, presented to the hospital at 27 weeks of gestation with nonspecific abdominal pain, vomiting and generalised weakness for 3 days. At 20 weeks she had a tonsillectomy due to chronic tonsillitis refractory to medical management and the histology was highly suspicious of T-NHL. She also had cervical lymphadenopathy and had been planned for a biopsy for

Sri Lanka Journal of Obstetrics and Gynaecology 2021; 43: 63-66

DOI: http://doi.org/10.4038/sljog.v43i1.7967

${ }^{a}$ Consultant Obstetrician and Gynaecologist, Base Hospital, Medirigiriya, Sri Lanka.

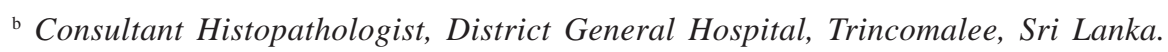

c Medical Officer in Obstetrics and Gynaecology, Base Hospital, Medirigiriya, Sri Lanka.

Correspondence: SK, e-mail: sajithkodithuwakku@gmail.com

(iD https://orcid.org/0000-0003-4063-6786

Received 26 $6^{\text {th }}$ December 2020

Accepted $25^{\text {th }}$ February 2021

This is an open-access article distributed under the terms of the Creative Commons Attribution 4.0 International License, which permits unrestricted use, distribution and reproduction in any medium provided the original author and source are credited. 
confirmation of the diagnosis. However, she defaulted follow up and was not seen until she presented with the acute illness. On examination, there were no localising signs or overt features of sepsis. Her liver enzymes were slightly elevated with aspartate transaminase(AST) and alanine transaminase(ALT) in 200s. Other initial blood investigations including bilirubin level, white cell count, inflammatory markers and renal function test were normal. The patient became agitated and confused within a few hours and deteriorated quickly. Therefore, she was admitted to the Intensive Care Unit (ICU) for monitoring and further care. She had a CT brain done due to acute confusion, which was also normal. On the repeated blood work, her AST and ALT had risen to 400s with a marginally elevated bilirubin level. Inputs were sought from multiple disciplines including general medicine, oncology and haematology for her management.
Despite the efforts, she continued to deteriorate and required three inotropes to maintain circulation by the end of the day. A collective decision was made to deliver the foetus hoping it would improve maternal circulation as well it would give a fair chance to the baby to survive. A $1.2 \mathrm{~kg}$ live baby was delivered by hysterotomy in the ICU. The procedure was uncomplicated and the patient managed to barely survive with intense support for another 2 days and succumbed. The baby required ventilator support at first, but discharged in good condition after 4 weeks.

Postmortem examination of the liver revealed microvesicular steatosis and intracellular cholestasis, which are suggestive of AFLD in pregnancy (Figure 1). Histology of cervical lymph nodes confirmed the presence of a T-NHL, which was supplemented by immunohistochemistry (Figure 2).

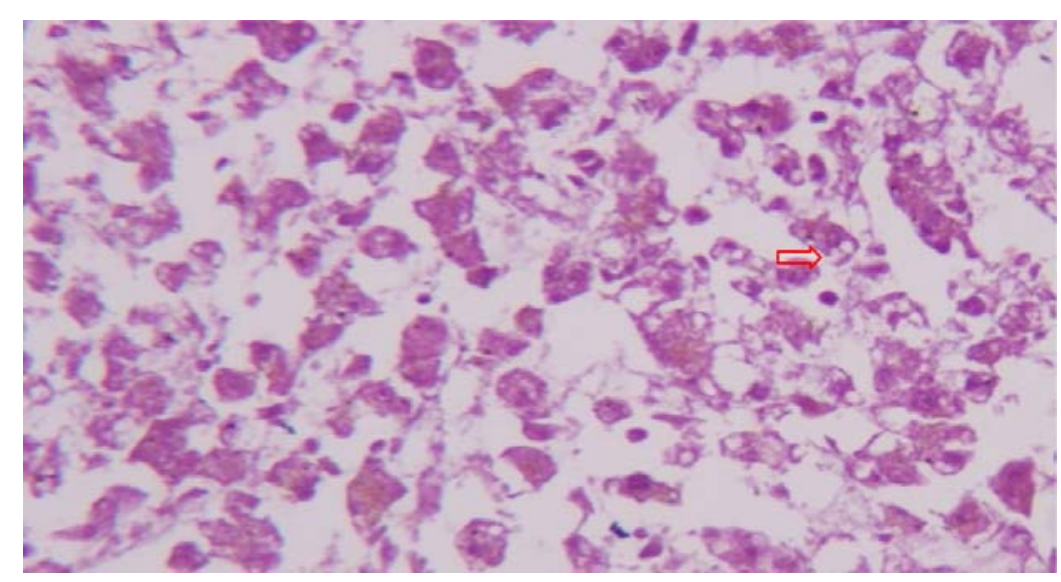

Figure 1. Microvesicular steatosis(red arrow) and cholestasis present in hepatocytes.

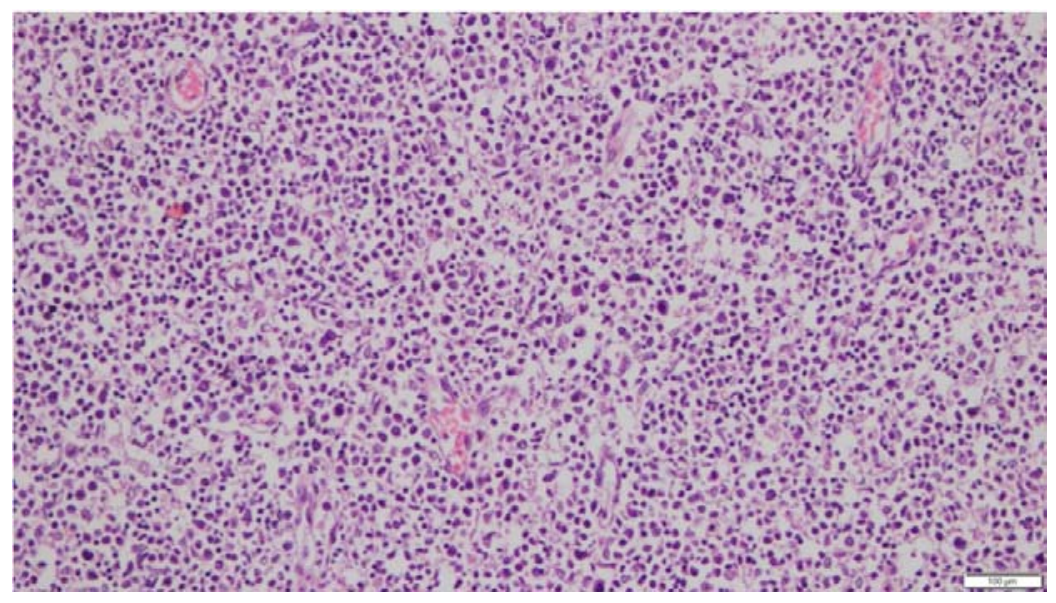

Figure 2. High grade T-NHL of a cervical lymph node. 


\section{Discussion}

Acute fatty liver disease in pregnancy usually presents in the third trimester and rarely can present in the postpartum period or the late second trimester like in this case. Diagnosis is made on clinical features, biochemistry, radiological and histological features using Swansea criteria (Table 1).

Presence of six or more features listed, in the absence of other explanation, increases the likelihood of AFLD in pregnancy ${ }^{6}$. With AFLD, typically liver enzymes are elevated, with AST and ALT enzymes ranging from a minimal elevation to $1000 \mathrm{IU} / \mathrm{L}$, but usually staying in the 300-500 range. Bilirubin is almost universally elevated ${ }^{7}$. In retrospect, this patient had abdominal pain, vomiting, encephalopathy (manifested by agitation), elevated liver enzymes and bilirubin. During the hysterotomy, she was noted to have mild ascites and the postmortem revealed microvesicular steatohepatosis in the liver. Acute fatty liver disease in pregnancy was not considered as a differential diagnosis when managing this patient because she had an incompletely worked-out, aggressive form of NHL in the background, which may produce a similar clinical picture in its disseminated form. Furthermore, the fact that she had 3 uncomplicated pregnancies in the past, would have contributed to hinder AFLD from the list of possibilities.

On literature search, we could not find any relationship between AFLD in pregnancy and T-NHL.

It's difficult to say at this point if the T-NHL contributed to the unfavourable outcome and rapid course of the disease in this particular case.

Patients with AFLD in pregnancy may present with non-specific symptoms and their background clinical conditions may mask the diagnosis. However, some form of liver involvement is always seen from the beginning with AFLD. The maternal outcome in AFLD in pregnancy largely depends on prompt diagnosis and timely delivery of the fetus. Therefore, it is imperative for the clinicians to take a minute and see if the patients fulfill Swansea criteria for AFLD in pregnancy when they present with such symptoms, even if they have other diagnoses in their background, which may produce a similar clinical picture.

Table 1. Swansea criteria for AFLD in pregnancy

\begin{tabular}{|l|l|}
\hline Feature & Definition \\
\hline Clinical & $\begin{array}{l}\text { Vomiting } \\
\text { Abdominal pain } \\
\text { Polydipsia/ Polyuria } \\
\text { Encephalopathy }\end{array}$ \\
\hline Laboratory & $>0.8 \mathrm{mg} / \mathrm{dl}(14 \mathrm{kmol} / \mathrm{l})$ \\
Bilirubin & $<72 \mathrm{mg} / \mathrm{dl}(4 \mathrm{mmol} / \mathrm{l})$ \\
Hypoglycemia & $>5.7 \mathrm{mg} / \mathrm{dl}(340 \mathrm{kmol} / \mathrm{l})$ \\
Uric acid & $>11 * 106 / \mathrm{l}$ \\
Leukocytosis & Ammonia $>27.5 \mathrm{mg} / \mathrm{dl}(47 \mathrm{kmol} / \mathrm{l})$, Creatinine $>1.7 \mathrm{mg} / \mathrm{dl}$ (150 kmol/l) \\
Renal impairment & Prothrombin time (PT) $>14 \mathrm{~s}$ or activated partial thromboplastin time \\
Coagulopathy & (APTT) $>34 \mathrm{~s}$ \\
AST and ALT & $>42 \mathrm{IU} / \mathrm{l}$ \\
Bilirubin & $>0.8 \mathrm{mg} / \mathrm{dl}(14 \mathrm{kmol} / \mathrm{l})$ \\
Ultrasonography & Ascites or bright liver \\
Liver biopsy & Microvesicular steatosis \\
\hline
\end{tabular}




\section{References}

1. Woo SY, Fuller LM, Cundiff JH, et al. Radiotherapy during pregnancy for clinical stages IA-IIA Hodgkin's disease. Int J Radiat Oncol Biol Phys. 1992; 23(2): 407-412.

2. Horesh N, Horowitz NA. Does gender matter in non-hodgkin lymphoma? Differences in epidemiology, clinical behavior, and therapy. Rambam Maimonides Med J. 2014; 5(4):e0038. Published 2014 Oct 29. doi:10.5041/RMMJ.10172.

3. Lees CC, Tsirigotis M, Carr JVL and Richards MA. T cell non-Hodgkin's lymphoma presenting in the first trimester of pregnancy. Postgrad Med J. 1994; 70 (823): 371-2. PubMed | Google Scholar.

4. Mjahed K, Charra B, Hamoudi D, Noun M, Barrou
L. "Acute fatty liver of pregnancy". Archives of Gynecology and Obstetrics. 2006; 274 (6): 349353. doi:10.1007/s00404-006-0203-6. PMID 16868757.

5. Fesenmeier MF, Coppage KH, Lambers DS, Barton JR, Sibai BM. "Acute fatty liver of pregnancy in 3 tertiary care centers". American Journal of Obstetrics and Gynecology. 2005; 192 (5): 14161419. doi:10.1016/j.ajog.2004.12.035. PMID 15902124.

6. Ch'ng CL, Morgan M, Hainsworth I, Kingham JG: Prospective study of liver dysfunction in pregnancy in Southwest Wales. Gut 2002; 51: 876-80.

7. Ko H, Yoshida EM. "Acute fatty liver of pregnancy”. Canadian Journal of Gastroenterology. 2006; 20 (1): 25-30. 